\title{
Assessment of cardiovascular risk in post-menopausal women
}

\section{in Ghana [version 1; peer review: 1 approved, 1 approved with}

\section{reservations]}

\author{
Justice Afrifa1,2, Felix A. Botchway33, Yeboah Kwaku Opoku (B),5, Joyce Badohu1, \\ Henrietta Ekua Ocran1', Kwame Kumi Asare (iD) 4,6, Samuel Essien-Baidoo1 \\ ${ }^{1}$ Department of Medical Laboratory Sciences, College of Allied Health Sciences, University of Cape Coast, Cape Coast, Ghana \\ ${ }^{2}$ Scientific Research Centre, Second Affiliated Hospital of Harbin Medical University, Harbin Medical University, Harbin, China \\ ${ }^{3}$ Department of Chemical Pathology,, University of Ghana, Accra, Ghana \\ ${ }^{4}$ Department of Biomedical Sciences, School of Allied Health Sciences, College of Health and Allied Sciences, University of Cape \\ Coast, Cape Coast, Ghana \\ ${ }^{5}$ Biopharmaceutical Laboratory, College of Life Sciences, Northeast Agricultural University, Harbin, China \\ ${ }^{6}$ Department of Protozoology Institute of Tropical Medicine (NEKKEN), Nagasaki University, Nagasaki, Japan
}

V1 First published: 11 Jun 2019, 8:845

https://doi.org/10.12688/f1000research.19447.1

Latest published: 11 Jun 2019, 8:845

https://doi.org/10.12688/f1000research.19447.1

\section{Abstract}

Background: Cardiovascular diseases (CVD) continue to be a major cause of death among post-menopausal women. We sought to assess cardiovascular risk among pre- and post-menopausal women living within the Cape Coast Municipality by comparing the lipid profiles and other emerging biomarkers of CVD, i.e. the atherogenic index of plasma (AIP), visceral adiposity index (VAI), body adiposity index (BAI) and Castelli index I (CRI-I).

Methods: A comparative cross-section of 150 women (75 premenopausal women and 75 post-menopausal women) visiting the University of Cape Coast hospital for regular checkups were randomly recruited into the study. Socio-demographic and clinical characteristics of participants were obtained with the aid of a structured questionnaire. Blood pressure (BP) was measured and lipid profile was estimated using fasting blood samples. Other markers of cardiovascular risk such as BMI, AIP, VAI, BAI and CRI-I were estimated.

Results: We report elevated levels of total cholesterol (TC) $(p<0.0001)$, low density lipoprotein $(L D L)(p<0.0001)$, very low-density lipoprotein $(V L D L)(p=0.0021)$, triglycerides $(T G)(p<0.0001)$ and non-high-density lipoprotein (non-HDL-C) cholesterol $(p<0.0001)$ in post-menopausal women compared with pre-menopausal women. High-density lipoprotein $(\mathrm{HDL})(\mathrm{p}<0.0001)$ was, however, decreased in postmenopausal women. Mean AIP $(p<0.0001)$, VAI $(p<0.0001)$, BAI $(p<$ $0.0038)$ and CRI-I $(p<0.0001)$ were significantly increased in postmenopausal women compared to pre-menopausal women. We also

\section{Open Peer Review \\ Approval Status ? \\ 12 \\ version 1 \\ 11 Jun 2019
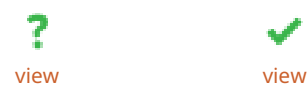 \\ 1. Bashu Dev Pardhe ID, Manmohan Memorial Institute of Health Sciences, Kathmandu, Nepal \\ 2. Christian Obirikorang (iD, Kwame Nkrumah University of Science and Technology (KNUST), Kumasi, Ghana}

Any reports and responses or comments on the article can be found at the end of the article. 
report a positive correlation of TC, TG, VLDL and non-HDL with atherogenic markers AIP, VAI and CRI-I in post-menopausal women. A negative correlation of HDL with AIP, VAI, and CR in post-menopausal women was also observed.

Conclusions: Menopause could lead to changes in lipid profile to atherogenicity with associated increase in the risk of CVD. Atherogenic markers such as AIP, VAI, BAI, and CR can serve as potential biomarkers for predicting CVD.

Keywords

Atherogenicity, menopause, Lipid profile, cardiovascular diseases

Corresponding author: Yeboah Kwaku Opoku (kyeboah95@neau.edu.cn)

Author roles: Afrifa J: Conceptualization, Writing - Original Draft Preparation, Writing - Review \& Editing; Botchway FA: Data Curation, Investigation, Methodology; Opoku YK: Data Curation, Formal Analysis, Investigation, Methodology, Writing - Original Draft Preparation, Writing - Review \& Editing; Badohu J: Data Curation, Formal Analysis, Investigation, Methodology; Ocran HE: Data Curation, Formal Analysis, Investigation, Methodology; Asare KK: Writing - Original Draft Preparation, Writing - Review \& Editing; Essien-Baidoo S: Supervision, Writing - Original Draft Preparation, Writing - Review \& Editing

Competing interests: No competing interests were disclosed.

Grant information: The author(s) declared that no grants were involved in supporting this work.

Copyright: $\odot 2019$ Afrifa J et al. This is an open access article distributed under the terms of the Creative Commons Attribution License, which permits unrestricted use, distribution, and reproduction in any medium, provided the original work is properly cited.

How to cite this article: Afrifa J, Botchway FA, Opoku YK et al. Assessment of cardiovascular risk in post-menopausal women in Ghana [version 1; peer review: 1 approved, 1 approved with reservations] F1000Research 2019, 8:845

https://doi.org/10.12688/f1000research.19447.1

First published: 11 Jun 2019, 8:845 https://doi.org/10.12688/f1000research.19447.1 


\section{Introduction}

Menopause is a permanent physiological state with cessation of menstruation attributable to the loss of ovarian function and reduction in the production of estrogen ${ }^{1}$. The average age of menopause is reported to be 51 years ${ }^{2}$ but the age of natural menopause may vary from 40 to 58 years. This phase is characterized by variety of changes in socio-cultural, physiological and psychological states. These changes culminate into myriad of symptoms including insomnia, sweating, hot flashes, depressive mood, vaginal dryness and general discomfort ${ }^{3}$.

Cardiovascular diseases (CVD) are the major cause of death among post-menopausal women ${ }^{4}$. Studies have shown that premenopausal women have a low risk of CVD as compared to men but after menopause the level of risk increases ${ }^{5}$. Epidemiological data have revealed elevated risk of CVD in postmenopausal females compared to men of the same age ${ }^{6}$. Estrogen is the major female hormone that regulates many aspects of a female's development. Reduced circulating estrogen levels impeded ovulation as results of under stimulation of the hypothalamus to release follicle stimulating hormones ${ }^{7,8}$. Estrogen is known to possess both anti-atherogenic and cardioprotective effect by maintaining high levels of high-density lipoprotein (HDL-C) coupled with decreasing low-density lipoprotein cholesterol (LDL-C), and triglycerides (TG) ${ }^{9}$. Several factors, including diabetes, hypertension, and atherosclerosis among others can lead to CVD in women. The World Health Organization (WHO) has ranked CVDs as the number one cause of death, with global estimation of about 17.7 million deaths in $2015^{10}$.

Current data have shown that Castelli risk index I and II which are estimated as TC/HDL-C and LDL/HDL-C ratios respectively predict cardiovascular risk accurately than conventional lipid profile indices such as serum TC and serum triglycerides ${ }^{11,12}$. Similarly, comparison of individual lipid ratios in subjects of the Framingham Heart Study unarguably indicates that lipid ratios are significantly more useful predictors of CVD than the individual levels of LDL or $\mathrm{HDL}^{12}$. Many clinical studies have also made efforts to introduce better markers of atherogenic dyslipidemia that can predict the risk of CVD to be useful for evaluating response to treatment instead of the classical $\operatorname{ratios}^{13}$. Notable among these markers is the atherogenic index of plasma, which has proven to be a strong marker for the prediction of atherosclerosis and coronary heart disease risk ${ }^{14}$.

Menopausal health has received little attention due to high illiteracy rate, poverty and a possible lack of understanding of the clinical dynamics associated with it, irrespective of the fact that menopause is a key risk factors for dyslipidemia which affects cardiovascular health of women. Compared with men, the diagnosis of CVD in women is difficult due to hormone-related changes and difference in sex in the clinical manifestation of CVD. Such limitations and challenges present the need for an increased consciousness of the significance of CVD as a major public health issue for older women. This study therefore sought to assess the cardiovascular risk between pre and post-menopausal woman in the Cape Coast municipality by comparing the lipid profiles and other emerging biomarkers of CVD such as atherogenic index of plasma visceral adiposity index and basal adiposity index.

\section{Methods}

Study area and population

We conducted this comparative cross-sectional study among a convenience sample of 150 women between June 2017 and August 2018 at Cape Coast, the capital of the Central Region of Ghana. No attempts were made to control for bias in recruitment. This Region covers an area of approximately 9826 square kilometres or $4.1 \%$ of Ghana's land area. The study participants were apparently healthy pre- and post-menopausal women.

\section{Inclusion criteria}

The inclusion criterion used for the study was healthy postmenopausal women aged 40-55 years serving as cases while premenopausal women within the age of 30-40 years were used as comparative controls.

\section{Exclusion criteria}

Those with known cardiovascular and metabolic diseases such as hypertension, diabetes, renal or hepatic disorders, menstrual disorders and those on hormonal replacement therapies were excluded from the study. Also, pregnant and lactating women, women with known thyroid diseases, heavy smokers and alcoholics were not included in the research.

\section{Ethical approval and consent to participate}

Ethical approval for the research was sought from the Institutional Review Board of University of Cape Coast (UCCIRB/ CHAS/2017/83). All information regarding the study including the purpose, risks, procedures, and benefits were made known to the participants before seeking for written informed consent.

\section{Blood sample collection, lipid profile and fasting blood glucose measurement}

From each participant, $4 \mathrm{~mL}$ of venous blood samples were collected from each participant with a sterilized syringe and needle after an overnight fast (12-14 hours) and dispensed into a gel separator tube. Blood samples were analyzed using a fully automated chemistry analyzer (Mindray BS240. Mindray Bio-Medical Electronics Co., Ltd) to estimate the total cholesterol (TC), low-density lipoprotein cholesterol (LDL-C), high-density lipoprotein cholesterol (HDL-C), VLDL, TG and non-HDL. Fasting blood glucose was measured with the URIT glucometer (URIT G26 ${ }^{\circledR}$, URIT Medical Electronic, UK).

\section{Anthropometric measurements}

For body mass index (BMI) estimation, height was measured to the nearest centimetre without shoes with a stadiometer (Seca 217, 40 Barn Street B5 5QB Birmingham, United Kingdom) and weight was measured to the nearest $0.1 \mathrm{~kg}$, with a bathroom scale (Zhongshan Camry Electronic Co. Ltd, Guangdong, China). BMI was calculated as a ratio of weight $(\mathrm{kg})$ to height squared $\left(\mathrm{m}^{2}\right)$. This was used to categorize participants as underweight $\left(<18 \mathrm{~kg} / \mathrm{m}^{2}\right)$, normal $\left(18-24 \mathrm{~kg} / \mathrm{m}^{2}\right)$, overweight $\left(25-29.9 \mathrm{~kg} / \mathrm{m}^{2}\right)$ and obese $\left(>30 \mathrm{~kg} / \mathrm{m}^{2}\right)$ according to WHO criteria ${ }^{15}$. 


\section{Measurement of blood pressure}

Blood pressure measurements were performed according to the American Heart Association recommendations ${ }^{16}$. Measurements of blood pressure were performed using an automatic validated device (Omron HEM711DLX, UK) on the superior left limb. The subjects were made to sit with the legs uncrossed and arm supported at the height of the heart with cuff adapted to the size of the arm. Blood pressure was measured as the mean values of duplicate measurements. Grading of hypertension recorded as follows; "normal" when the systolic blood pressure (SBP) was $<120 \mathrm{mmHg}$ and diastolic blood pressure (DBP) was $<80 \mathrm{mmHg}$ "pre-hypertension" when SBP $=120-139$ or $\mathrm{DBP}=80-89$ and "hypertension" when SBP $=140-159$ or $\mathrm{DBP}=90-99^{17}$.

\section{Atherogenic indices}

Atherogenic indices estimated included AIP (log (TG/HDL), visceral adiposity index $(\mathrm{VAI})\left(\mathrm{VAI}=\left(\frac{W C}{36.5+(1.89 \times B M I)}\right) \times\left(\frac{T G}{0.81}\right) \times\left(\frac{1.52}{H D L}\right)\right.$,

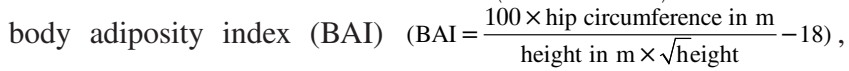
non-HDL(TC - HDL) and CRI-I(TC/HDL) $)^{18}$.

\section{Data analysis}

Data for the study were analyzed using GraphPad prism (6.01) and $\mathrm{R}$ statistical software package version 3.0.1. Exploratory analysis was done for descriptive statistical indices such as frequencies, percentages and mean \pm standard deviations. Tables were obtained from exploratory analysis. Student's t-test was performed to compare pre and post-menopausal groups for anthropometrics, lipid profiles and atherogenic indices. Fisher's exact test or Chi-square test were employed where deem fit to assess the association between proportions of variables in pre and post-menopausal groups. Crude and adjusted odds ratios (aOR) at 95\% confidence interval (CI) were evaluated for Fisher's exact test outcome. Correlation analysis was done using Spearman's rho moment correlation analysis for lipid profile and atherogenic indices among the study participants. Significance level was determined at $P<0.05$.

\section{Results}

\section{Participant background}

A total of 150 pre and post-menopausal women were enrolled into the study with a significantly older post-menopausal group (59.63 $\pm 7.419, \quad \mathrm{P}<0.0001)$ compared to the pre-menopausal group (32.28 \pm 8.820$)$. Also, the post-menopausal group had an elevated SBP $(\mathrm{P}=0.0003)$, DBP $(\mathrm{P}=0.0822)$, FBS $(\mathrm{P}=0.0004)$ as well as a higher BMI compared to the pre-menopausal women (Table 1). Complete demographic information, alongside all other variables measured, are available as Underlying data ${ }^{19}$.

\section{Cardiovascular and atherogenic markers}

Serum TC, TG and NON-HDL-C were significantly increased in post-menopausal women compared to pre-menopausal women $(\mathrm{p}<0.0001)$. In addition, there was an observed significant increase in LDL-C $(\mathrm{p}<0.0001)$ and VLDL $(\mathrm{p}=0.0021)$ levels in the postmenopausal women. In comparison with pre-menopausal women, atherogenic markers (AIP, VAI, BAI and CRI-I) were significantly elevated in post-menopausal women $(\mathrm{p}<0.0001)$ (Table 2$)$.

\begin{tabular}{|c|c|c|c|}
\hline Variable & Pre- menopausal & Post-menopausal & p-value \\
\hline Age (years) & $32.28 \pm 8.820$ & $59.63 \pm 7.419$ & $<0.0001$ \\
\hline Weight (kg) & $61.16 \pm 10.08$ & $6.21 \pm 8.82$ & 0.4969 \\
\hline Height(m) & $1.59 \pm 0.06$ & $1.56 \pm 0.062$ & 0.0001 \\
\hline WC (cm) & $75.36 \pm 9.67$ & $82.53 \pm 8.68$ & $<0.0001$ \\
\hline $\mathrm{HC}(\mathrm{m})$ & $0.93 \pm 0.13$ & $0.87 \pm 0.08$ & 0.2513 \\
\hline $\mathrm{WC} / \mathrm{HC}$ & $0.87 \pm 0.61$ & $0.95 \pm 0.09$ & 0.9733 \\
\hline BMI $\left(\mathrm{kg} / \mathrm{m}^{2}\right)$ & $24 \pm 3.644$ & $25.57 \pm 2.883$ & 0.0039 \\
\hline Under weight & $5(6.7)$ & $1(1.3)$ & 0.0804 \\
\hline Normal & $40(53.3)$ & $33(44.0)$ & \\
\hline Overweight & $30(40.0)$ & $41(54.7)$ & \\
\hline $\mathrm{SBP}(\mathrm{mmHg})$ & $112.3 \pm 7.591$ & $116.7 \pm 6.960$ & 0.0003 \\
\hline $\mathrm{DBP}(\mathrm{mmHg})$ & $75.33 \pm 5.285$ & $76.8 \pm 4.976$ & 0.0822 \\
\hline FBS (mmol/L) & $5.515 \pm 0.6247$ & $5.865 \pm 0.5547$ & 0.0004 \\
\hline Low & $3(4.0)$ & $\mathrm{O}(0)$ & 0.1037 \\
\hline Normal & $31(41.3)$ & 25(33.3) & \\
\hline Pre-diabetes & $41(54.7)$ & $50(66.7)$ & \\
\hline
\end{tabular}

WC, waist circumference; $\mathrm{HC}$, hip circumference; WC/HC, waist to hip ratio; FBS, fasting blood sugar; BMI, body mass index; SBP, systolic blood pressure; DBP, diastolic blood pressure. 


\section{Table 2. Comparison of Lipid profile and other atherogenic biomarkers among pre and post-menopausal women.}

\begin{tabular}{|l|l|l|l|}
\hline Variable & Pre-Menopause & Post-Menopause & P-value \\
\hline TC $(\mathrm{mmol} / \mathrm{L})$ & $4.130 \pm 0.4758$ & $5.889 \pm 0.6545$ & $<0.0001$ \\
\hline $\mathrm{HDL}-\mathrm{C}(\mathrm{mmol} / \mathrm{L})$ & $1.941 \pm 0.5831$ & $1.111 \pm 0.2106$ & $<0.0001$ \\
\hline LDL-C (mmol/L) & $3.036 \pm 0.6797$ & $4.449 \pm 0.7094$ & $<0.0001$ \\
\hline VLDL $(\mathrm{mmol} / \mathrm{L})$ & $0.3381 \pm 0.4217$ & $0.5043 \pm 0.1803$ & 0.0021 \\
\hline TG $(\mathrm{mmol} / \mathrm{L})$ & $0.576 \pm 0.2869$ & $1.087 \pm 0.3612$ & $<0.0001$ \\
\hline $\mathrm{NON}-\mathrm{HDL}(\mathrm{mmol} / \mathrm{L})$ & $2.189 \pm 0.8091$ & $4.778 \pm 0.7299$ & $<0.0001$ \\
\hline AIP & $-0.5333 \pm 0.2251$ & $-0.02147 \pm 0.1839$ & $<0.0001$ \\
\hline VAl & $0.6431 \pm 0.9652$ & $1.907 \pm 1.907$ & $<0.0001$ \\
\hline BAI & $28.31 \pm 6.576$ & $31.08 \pm 4.847$ & 0.0038 \\
\hline CRI-I & $2.366 \pm 1.009$ & $5.523 \pm 1.318$ & $<0.0001$ \\
\hline
\end{tabular}

TC, total cholesterol; HDL-C, high-density lipoprotein-cholesterol; LDL-C, low-density lipoprotein-cholesterol; VLDL, very low-density lipoprotein; TG triglycerides; AIP, atherogenic index of plasma; BAI, body adiposity index; CRI-I, Castelli index I.
Higher levels of TC, LDL-C, AIP, BAI and CRI-I, as well as low levels of HDL-C, were all crudely associated with postmenopausal women $(\mathrm{p}<0.0001)$. However when the data was adjusted for age and BMI, only elevated levels of $\mathrm{TC}[\mathrm{aOR}=76.58$ (95\% CI $=5.880-2439.396), \quad \mathrm{P}=0.0032], \quad \mathrm{LDL}-\mathrm{C} \quad[\mathrm{aOR}=11.76$ (95\% CI $=1.934-90.816), \quad \mathrm{P}=0.011], \quad \mathrm{BAI} \quad[\mathrm{aOR}=41.19$ (95\% CI $=6.7511-321.0692), \quad \mathrm{P}=0.0001], \quad \mathrm{CRI}-1 \quad[\mathrm{aOR}=818.824$ (95\% CI $=51.900-29515.961), \mathrm{P}=0.0001]$ as well as low levels of HDL-C $[\mathrm{aOR}=11.76(95 \% \mathrm{CI}=1.934-90.816), \mathrm{P}=0.011]$ were significantly associated with post-menopausal women (Table 3 ).

In post-menopausal women, we report a positive correlation of TC with all the cardiovascular and atherogenic markers except HDL-C whilst HDL-C on the other hand showed a significant negative correlation with all the atherogenic and cardiovascular markers with the exception of BAI, which wasn't significant (Figure 1).

\section{Discussion}

Although CVD is the major cause of death and disability in women, it usually starts about 10 years late in men of the same age. It is also true that CVD are the major cause of mortality in post-menopausal women ${ }^{4}$. The patterns of dyslipidemia that leads to CVD and its associated complications have been linked with hormonal changes associated with menopause. Estrogen is known to possess both anti-atherogenic and cardioprotective effect by maintaining an acceptable balance between pro/ anti-atherogenic and cardiovascular risk markers 9 . We therefore sought to assess cardiovascular and atherogenic risk among pre and post-menopausal women in the Cape-Coast municipality.

In comparison to pre-menopausal women, we report elevated levels of TC $(p<0.0001)$, VLDL, TG $(p<0.0001)$, LDL-C $(p<0.0001)$ and NON-HDL cholesterol $(\mathrm{p}<0.0001)$ in post-menopausal women. This is in line with earlier findings by Pardhe et al., who also reported significantly increased levels of TG, TC, LDL-C and reduced levels of HDL-C among Nepalese women ${ }^{4}$. Adverse changes in lipids and lipoprotein independent of age has been linked to mmenopause ${ }^{20}$. Among all the risk factors for CVD, the major indication suggests an association of estrogen with the observed discrepancies in lipids and lipoproteins ${ }^{12}$. Earlier studies have reported an increase in the release of free fatty acids into circulation due to high-fat accumulation leading to elevated hepatic triglycerides synthesis ${ }^{21}$. In addition, a reduction in estrogen after menopause increases plasma lipoprotein lipase (LPL) and hepatic TG lipase activity thereby causing accumulation of plasma LDL-C ${ }^{22}$. However, HDL-C was significantly decreased in post-menopausal women which is in tandem with the findings of previous studies ${ }^{23,24}$. Available evidence shows that as HDL-C increases by $0.026 \mathrm{mmol} / \mathrm{ml}$, there is a reduction in risk of cardiovascular diseases, with a $4.7 \%$ decrease in mortality rate of $\mathrm{CVD}^{25}$. Changes in plasma lipid is known to partly increase the incidence of cardiovascular disease following menopausal transition ${ }^{20,24}$.

Newly emerging atherogenic markers such as AIP, VAI, BAI and CRI-I have been used to assess cardiovascular risk and atherogenicity among various disease states including hypertension ${ }^{26}$, diabetics $^{27}$ and among HIV patients ${ }^{11}$. Our results revealed that, markers of atherogenicity including AIP $(\mathrm{p}<0.0001)$, VAI $(\mathrm{p}<0.0001)$, BAI $(\mathrm{p}<0.0038)$ and CRI-I $(\mathrm{p}<0.0001)$ were significantly increased in post-menopausal women. This is in line with a study by Nwagha et al., which reported a significantly reduced AIP levels among pre-menopausal women confirming the alteration of lipid profile in menopause ${ }^{26}$. The use of lipid ratios as prognosticators of cardiovascular risk cannot be overemphasized. In fact, variations in lipid ratios such as CRI-I and CRI-II have been reported to be better predictors of risk reduction in coronary heart disease compared to the absolute lipoproteins or lipids ${ }^{28}$. 


\begin{tabular}{|c|c|c|c|c|}
\hline \multirow{2}{*}{$\begin{array}{l}\text { Variable } \\
\text { TC }\end{array}$} & \multicolumn{2}{|l|}{ Crude OR $(95 \% \mathrm{Cl})$} & \multirow[t]{2}{*}{ aOR $(95 \% \mathrm{Cl})$} & \multirow[t]{2}{*}{ P-value } \\
\hline & & & & \\
\hline LOW & $0.4286(0.01635$ to 11.23$)$ & 0.7115 & NA & \\
\hline Normal & *reference & & & \\
\hline High & $474.5(59.09$ to 3810$)$ & $<0.0001$ & $76.58(5.880-2439.396)$ & 0.0032 \\
\hline \multicolumn{5}{|l|}{ HDL-C } \\
\hline Low & $24.65(7.277$ to 78.69$)$ & $<0.0001$ & $11.76(1.934-90.816)$ & 0.011 \\
\hline Normal & ${ }^{*}$ reference & & & \\
\hline \multicolumn{5}{|l|}{ LDL-C } \\
\hline LOW & $6.83(0.3596$ to 129.7$)$ & 0.0855 & $1.164 \times 10^{-5}\left(0.162-2.022 \times 10^{4}\right)$ & 0.996 \\
\hline Normal & ${ }^{*}$ reference & & & \\
\hline High & 29.06(3.793 to 222.6) & $<0.0001$ & $16.86(1.641-433.443)$ & 0.0343 \\
\hline \multicolumn{5}{|l|}{ VLDL } \\
\hline Normal & ${ }^{*}$ reference & & & \\
\hline High & $0.7396(0.1597$ to 3.425$)$ & 0.6987 & $4.32 \times 10^{7}\left(1.992 \times 10^{-60}-1.789 \times 10^{40}\right)$ & 0.993 \\
\hline \multicolumn{5}{|l|}{ TG } \\
\hline Low & $\begin{array}{c}9.65 \times 10^{-9} \text { (NA to } \\
\left.2.67 \times 10^{71}\right)\end{array}$ & 0.933 & $4.73 \times 10^{-8}\left(2.5 \times 10^{-9}, 1.379 \times 10^{71}\right)$ & 0.993 \\
\hline Normal & ${ }^{*}$ reference & & & \\
\hline High & $1.808(0.1601$ to 20.42$)$ & 0.6272 & $15.77(0.122-15974.386)$ & 0.336 \\
\hline \multicolumn{5}{|l|}{ AIP } \\
\hline low & $0.005(0.001$ to 0.02$)$ & 0.0001 & $0.262(0.020-3.046)$ & 0.2885 \\
\hline normal & ${ }^{*}$ reference & & & \\
\hline high & $4.103(1.372$ to 11.76$)$ & 0.0218 & $2.61(0.363-18.652)$ & 0.334 \\
\hline \multicolumn{5}{|l|}{ BAI } \\
\hline low & $0.4(0.07202$ to 2.246$)$ & 0.2949 & $0.16(0.0045-39194)$ & 0.27 \\
\hline normal & ${ }^{*}$ reference & & & \\
\hline high & $54.17(19.46$ to 133$)$ & $<0.0001$ & $41.19(6.7511-321.0692)$ & 0.0001 \\
\hline \multicolumn{5}{|l|}{ CRI-I } \\
\hline low & $0.5039(0.02176$ to 11.67$)$ & 0.6654 & $7.02 \times 10^{-6}\left(\mathrm{NA}-8.35 \times 10^{112}\right)$ & 0.9965 \\
\hline normal & ${ }^{*}$ reference & & & \\
\hline high & $467.2(87.58$ to 2492$)$ & $<0.0001$ & $818.824(51.900-29515.961)$ & $<0.0001$ \\
\hline
\end{tabular}

$\mathrm{NA}$, odds ratio value not given by $\mathrm{R}$ statistical package; aOR, age- and $\mathrm{BMI}$-adjusted odds ratio; $\mathrm{Cl}$, confidence interval; TC, total cholesterol; HDL-C, high-density lipoprotein-cholesterol; LDL-C, low-density lipoprotein-cholesterol; VLDL, very low-density lipoprotein; TG, triglycerides; AIP, atherogenic index of plasma; BAI, body adiposity index; CRI-I, Castelli index I.

Higher levels of TC, LDL-C, AIP, BAI and CRI-I as well as low levels of HDL-C were all crudely associated with postmenopausal women; however, after correction for age and BMI, AIP was not significantly associated to postmenopausal status with a marked reduction in the significance levels of the other parameters (Table 3). This confirms the significant intersection between cardiovascular risk and aging ${ }^{29}$. We also report a positive correlation of TC, TG, and VLDL with atherogenic markers AIP, VAI and CRI-1 in post-menopausal women. Upsurge in the levels of TG in isolation has been shown to increase AIP in women than in men but its influence can be neutralized by the levels of $\mathrm{HDL}^{30}$. Others have reported an association of CVD progression with the size of LDL-C and HDL-C, with the lesser size showing great atherogenic potential $^{31}$. There is indeed a strong relationship between cholesterol etherification rate in HDL plasma (FERHDL) and 


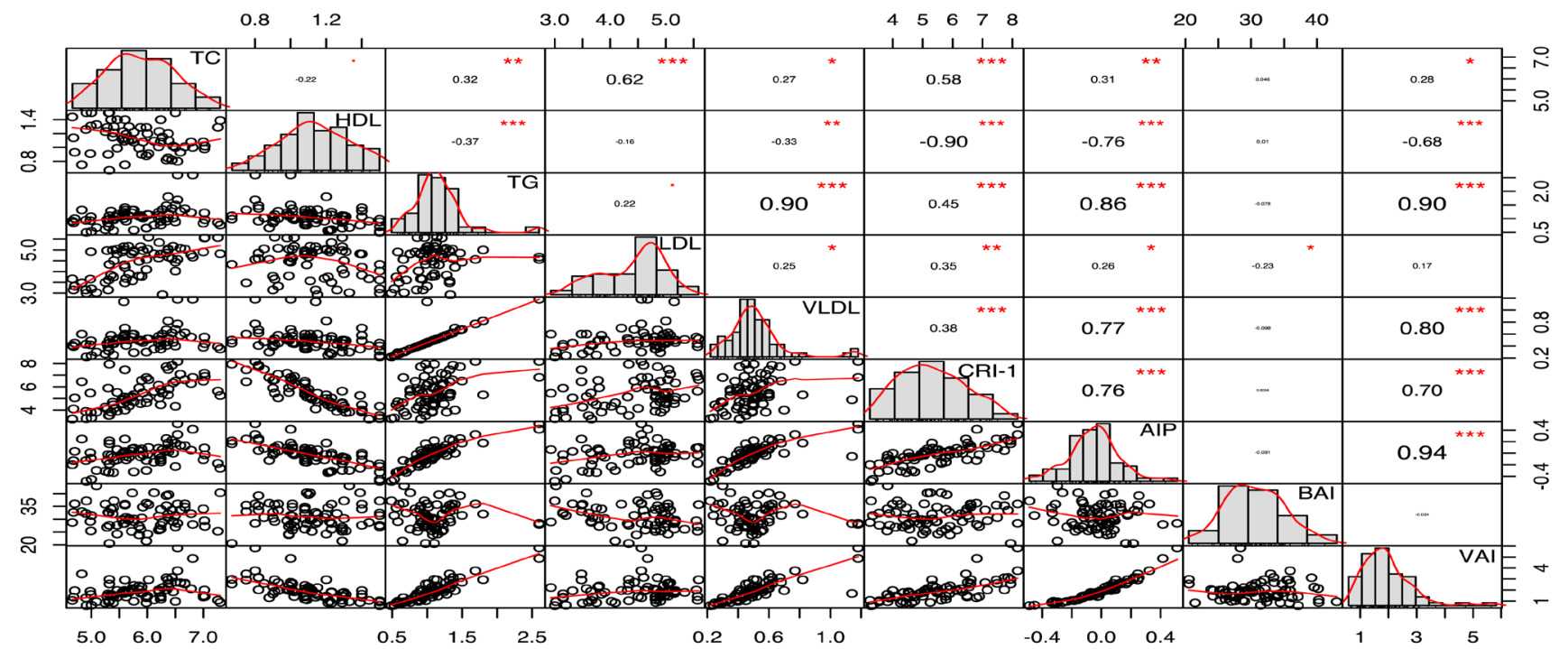

Figure 1. Scatter plot and correlation matrix between lipid profile and atherogenic markers among Post-menopausal women.

lipoprotein particle sizes, which is considered as a risk marker of coronary artery diseases. Lately, VAI has demonstrated to be a potent marker of adipose distribution and function indirectly conveying cardiometabolic risk $^{32}$. Among post-menopausal women, VAI was shown to predict cardiometabolic risk in association with visceral fat $^{33}$ while positively correlating with peripheral glucose usage during euglycemic hyperinsulinemic clamp $^{32}$. Among our study population, post-menopausal women showed increased body adiposity with a high percentage of body fat than pre-menopausal counterparts. An easy but effective determination of adiposity is needed to assess the magnitude of cardiovascular disease for the development of suitable management and preventive strategies. Confirmatory studies in different ethnicities have consistently revealed the overestimation and underestimation of adiposity at low and higher body fat percentages, respectively, by $\mathrm{BAI}^{34}$. Therefore, it is important to carefully interpret BAI values along with other anthropometric and cardiovascular markers.

Our results also indicated there was a significant increase in BMI, blood pressure and fasting blood sugar in post-menopausal women in contrast with pre-menopausal women. The increase may be attributed to the reduction in the production of estrogen, which may be associated with amplified cardiovascular risk in post-menopausal women. Surgical or naturally induced menopause increases the risk of $\mathrm{CVD}^{35}$ and the changeover may be associated with changes in body composition, with a considerable increase in the waist-to-hip ratio during menopause coupled to a possible increase in $\mathrm{BMI}^{36}$. Research has demonstrated the upsurge in the release of nitric oxide and the production of prostacyclin within the arterial endothelial cells by estrogen, culminating into the induction of a vasodilatory effect leading to a drop in $\mathrm{BP}^{37}$. Furthermore, estrogen again reduces the synthesis of thromboxane $\mathrm{A}_{2}$ by platelets with vasoconstriction properties ${ }^{38}$. Hence the absence or a reduction in the estrogen levels during menopause may increase blood pressure due to an increase in peripheral resistance. Also, when estrogen production is low, there is reduced stimulation of the liver to synthesize renin. This is a rate-limiting step in the reninangiotensin-aldosterone system leading to vasoconstriction with subsequent increase in blood pressure ${ }^{39}$. On the other hand, urbanization, affluence, changing dietary habits and sedentary lifestyles can also be implicated for the above findings ${ }^{40}$. Even though a significant association of increased cardiovascular risk with post-menopausal status was found in this study, our findings may be limited by the smaller sample size used and hence a larger sample size would have provided more stability to our conclusions.

\section{Conclusion}

Menopause could lead to changes in lipid profile in the direction of atherogenicity and increase the risk of CVDs. Atherogenic markers such as AIP, VAI, BAI, and CR can serve as potential biomarkers for predicting CVD and can be used together with other markers.

\section{Data availability}

Underlying data

Zenodo: Assessment of cardiovascular risk in post-menopausal women in Ghana. http://doi.org/10.5281/zenodo.3228917 ${ }^{19}$.

\section{Grant information}

The author(s) declared that no grants were involved in supporting this work. 
1. Sherwin B: Menopause: Myths and realities. Psychological aspects of women's health care, the interface between psychiatry and obstetrics and gynecology. 1993; 227-248.

Reference Source

2. Trishala A, Priya VV, G R: Comparative assessment of lipid profile in pre- and post-menopausal women in Tuticorin district -a pilot study. Int J Pharm Bio SCi. 2016; 7(3): 1109-12.

Reference Source

3. Fernandez ML, Murillo AG: Postmenopausal Women Have Higher HDL and Decreased Incidence of Low HDL than Premenopausal Women with Metabolic Syndrome. Healthcare (Basel). Multidisciplinary Digital Publishing Institute. 2016; 4(1): pii: E20.

PubMed Abstract | Publisher Full Text | Free Full Text

4. Pardhe BD, Ghimire S, Shakya J, et al.: Elevated Cardiovascular Risks among Postmenopausal Women: A Community Based Case Control Study from Nepal. Biochem Res Int. 2017; 2017: 3824903.

PubMed Abstract | Publisher Full Text | Free Full Text

5. Couderc R, Maachi M: [Lipoprotein(a): risk factor for atherosclerotic vascular disease important to take into account in practice]. Ann Biol Clin (Paris). 1999; 57(2): 157-67.

PubMed Abstract

6. Yamamoto A, Horibe $\mathrm{H}$, Mabuchi $\mathrm{H}$, et al:: Analysis of serum lipid levels in Japanese men and women according to body mass index. Increase in risk of atherosclerosis in postmenopausal women. Research Group on Serum Lipid Survey 1990 in Japan. Atherosclerosis. 1999; 143(1): 55-73. PubMed Abstract | Publisher Full Text

7. Randolph JF Jr, Sowers M, Bondarenko IV, et al.: Change in estradiol and follicle-stimulating hormone across the early menopausal transition: effects of ethnicity and age. J Clin Endocrinol Metab. 2004; 89(4): 1555-1561.

PubMed Abstract | Publisher Full Text

8. Groom GV, Griffiths K: Effect of the anti-oestrogen tamoxifen on plasma levels of luteinizing hormone, follicle-stimulating hormone, prolactin, oestradiol and progesterone in normal pre-menopausal women. J Endocrinol. 1976; 70(3): 421-428. PubMed Abstract | Publisher Full Text

9. Adashi EY: The climacteric ovary as a functional gonadotropin-driven androgen-producing gland. Fertil Steril. 1994; 62(1): 20-27.

PubMed Abstract | Publisher Full Text

10. WHO: Cardiovascular diseases. 2017.

Reference Source

11. Adedokun AK, Olisekodiaka MJ, Adeyeye DA, et al.: Castelli Risk Index, Atherogenic Index of Plasma, and Atherogenic Coefficient: Emerging Risk Predictors of Cardiovascular Disease in HIV-Treated Patients. 2017. Reference Source

12. Manninen $\mathrm{V}$, Tenkanen $\mathrm{L}$, Koskinen $\mathrm{P}$, et al.: Joint effects of serum triglyceride and LDL cholesterol and HDL cholesterol concentrations on coronary heart disease risk in the Helsinki Heart Study. Implications for treatment. Circulation. 1992; 85(1): 37-45.

PubMed Abstract | Publisher Full Text

13. Khazaál MS: Atherogenic Index of Plasma (AIP) as a parameter in predicting cardiovascular risk in males compared to the conventional dyslipidemic indices (cholesterol ratios). Karbala J Med. 2013; 6(1): 1506-1513. Reference Source

14. Njajou OT, Kanaya AM, Holvoet P, et al:: Association between oxidized LDL, obesity and type 2 diabetes in a population-based cohort, the Health, Aging and Body Composition Study. Diabetes Metab Res Rev. 2009; 25(8): 733-739. PubMed Abstract | Publisher Full Text | Free Full Text

15. World Health Organization: Obesity: preventing and managing the global epidemic. World Health Organization. 2000.

Reference Source

16. Kirkendall WM, Burton AC, Epstein FH, et al.: Recommendations for human blood pressure determination by sphygmomanometers. Circulation. 1967 36(6): 980-988.

PubMed Abstract | Publisher Full Text

17. Verdecchia P, Angeli F: [The Seventh Report of the Joint National Committee on the Prevention, Detection, Evaluation and Treatment of High Blood Pressure: the weapons are ready]. Rev Esp Cardiol. 2003; 56(9): 843-847. PubMed Abstract

18. Nansseu JR, Moor VJ, Nouaga ME, et al.: Atherogenic index of plasma and risk of cardiovascular disease among Cameroonian postmenopausal women. Lipids Health Dis. 2016; 15(1): 49.

PubMed Abstract | Publisher Full Text | Free Full Text

19. Opoku YK, Afrifa J: Assessment of cardiovascular risk in post-menopausa women in Ghana [Data set]. Zenodo. 2019.

20. Stevenson JC, Crook D, Godsland IF: Influence of age and menopause on serum lipids and lipoproteins in healthy women. Atherosclerosis. 1993; 98(1): 83-90. PubMed Abstract | Publisher Full Text
21. Tankó LB, Bagger YZ, Qin G, et al.: Enlarged waist combined with elevated triglycerides is a strong predictor of accelerated atherogenesis and related cardiovascular mortality in postmenopausal women. Circulation. 2005; 111(15): 1883-1890.

PubMed Abstract | Publisher Full Text

22. Wakatsuki A, Okatani $\mathrm{Y}$, Ikenoue N, et al:: Effect of lower dose of oral conjugated equine estrogen on size and oxidative susceptibility of low-density lipoprotein particles in postmenopausal women. Circulation. 2003; 108(7): 808-813. PubMed Abstract | Publisher Full Text

23. Jensen J, Nilas L, Christiansen C: Influence of menopause on serum lipids and lipoproteins. Maturitas. 1990; 12(4): 321-331.

PubMed Abstract | Publisher Full Text

24. Matthews KA, Meilahn E, Kuller LH, et al:: Menopause and risk factors for coronary heart disease. N Engl J Med. 1989; 321(10): 641-646. PubMed Abstract | Publisher Full Text

25. Okonofua FE, Lawal A, Bamgbose JK: Features of menopause and menopausal age in Nigerian women. Int J Gynaecol Obstet. 1990; 31(4): 341-345. PubMed Abstract | Publisher Full Text

26. Nwagha UI, Ikekpeazu EJ, Ejezie FE, et al:: Atherogenic index of plasma as useful predictor of cardiovascular risk among postmenopausal women in Enugu, Nigeria. Afr Health Sci. 2010; 10(3): 248-52. PubMed Abstract | Free Full Text

27. Okpa HO, Enang OE, Effa EE, et al:: Comparative analysis of atherogenic index of plasma and its relationship with cardiovascular risk among patients with diabetes mellitus and concurrent diabetes mellitus with hypertension attending endocrinology clinic in a tertiary hospital south-south Nigeria. atherosclerosis. 2015; 13(15): 16 Reference Source

28. Millán J, Pintó X, Muñoz A, et al.: Lipoprotein ratios: Physiological significance and clinical usefulness in cardiovascular prevention. Vasc Health Risk Manag. 2009; 5: 757-65.

PubMed Abstract | Publisher Full Text | Free Full Text

29. North BJ, Sinclair DA: The intersection between aging and cardiovascular disease. Circ Res. 2012; 110(8): 1097-1108.

PubMed Abstract | Publisher Full Text | Free Full Text

30. Stensvold I, Tverdal A, Urdal P, et al:: Non-fasting serum triglyceride concentration and mortality from coronary heart disease and any cause in middle aged Norwegian women. BMJ. 1993; 307(6915): 1318-1322. PubMed Abstract | Publisher Full Text | Free Full Text

31. Drexel H, Amann FW, Rentsch K, et al: Relation of the level of high-density lipoprotein subfractions to the presence and extent of coronary artery disease. Am J Cardiol. 1992; 70(4): 436-440. PubMed Abstract | Publisher Full Text

32. Amato MC, Giordano C: Visceral adiposity index: an indicator of adipose tissue dysfunction. Int J Endocrinol. 2014; 2014: 730827. PubMed Abstract | Publisher Full Text | Free Full Text

33. Amato MC, Giordano C, Pitrone M, et al:: Cut-off points of the visceral adiposity index (VAI) identifying a visceral adipose dysfunction associated with cardiometabolic risk in a Caucasian Sicilian population. Lipids Health Dis. 2011; 10(1): 183.

PubMed Abstract | Publisher Full Text | Free Full Text

34. Ramírez-Vélez R, Correa-Bautista JE, González-Ruíz K, et al.: Body Adiposity Index Performance in Estimating Body Fat Percentage in Colombian College Students: Findings from the FUPRECOL-Adults Study. Nutrients. 2017; 9(1): pii: E40. PubMed Abstract | Publisher Full Text | Free Full Text

35. Kumar S, Shah C, Oommen E: Study of cardiovascular risk factors In pre and postmenopausal women. Int J Pharma Sci Res. 2012; 3(12): 560-570. Reference Source

36. Walton C, Lees B, Crook D, et al.: Body fat distribution, rather than overall adiposity, influences serum lipids and lipoproteins in healthy men independently of age. Am J Med. 1995; 99(5): 459-464. PubMed Abstract | Publisher Full Text

37. Tostes RC, Nigro D, Fortes ZB, et al:: Effects of estrogen on the vascular system. Braz J Med Biol Res. 2003; 36(9): 1143-1158. PubMed Abstract | Publisher Full Text

38. Cheang A, Sitruk-Ware R, Samsioe G: Transdermal oestradiol and cardiovascular risk factors. Br J Obstet Gynaecol. 1994; 101(7): 571-581. PubMed Abstract | Publisher Full Text

39. Atlas SA: The renin-angiotensin aldosterone system: pathophysiological role and pharmacologic inhibition. J Manag Care Pharm. 2007; 13(8 Supp B): 9-20. PubMed Abstract | Publisher Full Text

40. Garg B, Yadav N, Vardhan H, et al.: Asymptomatic obese hypertensives and need of routine echocardiography for left ventricular mass assessment and treatment. J Clin Diagn Res. 2013; 7(8): 1599-603. PubMed Abstract | Publisher Full Text | Free Full Text 


\section{Open Peer Review}

\section{Current Peer Review Status:}

\section{Version 1}

Reviewer Report 04 November 2019

https://doi.org/10.5256/f1000research.21320.r49748

(c) 2019 Obirikorang C. This is an open access peer review report distributed under the terms of the Creative Commons Attribution License, which permits unrestricted use, distribution, and reproduction in any medium, provided the original work is properly cited.

\section{Christian Obirikorang}

Department of Molecular Medicine, School of Medical Sciences, Kwame Nkrumah University of Science and Technology (KNUST), Kumasi, Ghana

\section{Overview and General Recommendations:}

Thank you for the opportunity to review this manuscript which highlights the need for CVD risk assessment among postmenopausal women. Fat mass accumulation is one of the significant changes that occur with advancing age and its peaks around the menopausal, and it is associated with metabolic and haemodynamic derangement. The research interests of the paper is that it adds to already existing knowledge on menopause and CVD risk. Despite the fact that menopausal transition is associated with physiological changes which affects the health status of women, little data exist in Ghana. Thus highlighting the relevance of the paper in context.

I found the paper to be overall well written and much of it to be well described. I felt confident that the authors executed careful and thorough processing of methods to generate the data. The design of the study combined with data processing strategy makes the data set seem quite useful for the purpose. However, there are few concerns which a minor revision is warranted.

First, the authors placed too much emphasis on lipids and anthropometry given little attention to the constellation of metabolic abnormalities (also called metabolic syndrome) and hypertension which are potent indicators of CVD. Lipids abnormalities or atherogenic indices alone does not explain $100 \%$ of CVD risk prevalence among postmenopausal women. Dyslipidaemia increases the risk of coronary artery disease among and lipid peroxidation promote atherosclerosis. Thus making the single emphasis on dyslipidemia relevant. However, for general CDD risk, I strongly recommend that the authors should include MetS and hypertension, which will give the relevance of the study in context.

\section{Minor Revisions:}

At the abstract section, the authors should correct "comparative cross-section" and change it to 
"comparative cross-sectional study".

At the results section, the mean blood pressure were within the recommended range for both groups. Thus, the first sentence should be revise: Also postmenopausal group had elevated BP should be change to "a higher BP levels were observed among postmenopausal women...... or something similar.

Is the work clearly and accurately presented and does it cite the current literature? Yes

Is the study design appropriate and is the work technically sound? Yes

Are sufficient details of methods and analysis provided to allow replication by others? Yes

If applicable, is the statistical analysis and its interpretation appropriate? Yes

Are all the source data underlying the results available to ensure full reproducibility? Yes

Are the conclusions drawn adequately supported by the results? Yes

Competing Interests: No competing interests were disclosed.

Reviewer Expertise: Chemical Pathology

I confirm that I have read this submission and believe that I have an appropriate level of expertise to confirm that it is of an acceptable scientific standard.

Reviewer Report 24 June 2019

\section{https://doi.org/10.5256/f1000research.21320.r49750}

(C) 2019 Pardhe B. This is an open access peer review report distributed under the terms of the Creative Commons Attribution License, which permits unrestricted use, distribution, and reproduction in any medium, provided the original work is properly cited.

\section{Bashu Dev Pardhe}

Department of Laboratory Medicine, Manmohan Memorial Institute of Health Sciences, Kathmandu, Nepal

The fact relies on that cardiovascular diseases (CVDs) are more prevalent in women after menopause; the researchers compare the lipid profile and atherogenic index in pre- and post- 
menopausal women.

They included a total of 150 women and estimated BP, FBG and lipid profile and finally, they determined the atherogenic markers like BMI, AIP, VAI, BAI, and CRI-I for the interpretation. They found a significant rise in lipid profiles except for HDL-C in post-menopausal women compared with pre-menopausal women. Mean AIP, VAI, BAI, and CRI-I $(p<0.0001)$ were significantly increased in post-menopausal women compared to pre-menopausal women. Higher levels of BAI and CRI-I were significantly associated with post-menopausal women after even adjusted for age and BMI factors.

At the same time, they reported a positive correlation of TC, TG, VLDL-C and non-HDL-C with atherogenic markers AIP, VAI and CRI-I in post-menopausal women. With these findings, they conclude that postmenopausal women have an adverse change in lipid parameters with an increased atherogenic index and they are more prone to have cardiovascular diseases.

\section{Comments:}

1. I found the manuscript interesting from an epidemiological point of view, which has the value to describe the lipid profile and atherogenicity in a group of pre and postmenopausal women from Ghana.

2. The age range for postmenopausal women was 40-55 years and for pre-menopausal was 30-40 years in the method section. In the result section (table 1), the mean age of postmenopausal women was reported to be $59.63 \pm 7.42$. How is this possible?

3. Socio-demographic factors like lifestyle interventions, education levels, social status, ethnicity, etc. may also influence the findings of this study. It will be useful (and interesting) to have a table with a more complete description of the women included in the study.

4. The author mentioned, "We, therefore, sought to assess cardiovascular and atherogenic risk among pre and post-menopausal women in the Cape-Coast municipality." The selection criteria and sample size do not reflect this statement.

5. The selection of the study population is not clearly defined. They approach for the convenient sampling, it is better to define inclusion and exclusion criteria for both pre and post-menopausal women separately. They recruit healthy women attending the hospital. The question remains why healthy women do attend the hospital. Were they completely healthy or apparently healthy?

6. Wide range of age of study population required larger sample size. Even author mention that the sample size limit this cross-sectional study, this relative smaller sample size may sometimes miss-lead the conclusion.

7. I recommend including significance of atherogenic index (AIP, VAI, and BAI) in introduction section because this study focused on the investigation of these parameters.

8. Table 1:

1. The average weight of post-menopausal women $(6.21 \pm 8.82 \mathrm{~kg})$ ?

2. I recommend using the same SI unit ( $\mathrm{cm}$ or $\mathrm{m}$ ) for height, WC and HC.

3. I recommend using the maximum 3 digits after decimal and uniform for all variables 
(all tables and figure).

4. Mention the criteria to define pre-diabetes in study population at least in the method section.

9. It is better to include the abbreviation section in the manuscript. Please use cardiovascular diseases (CVDs), very low-density lipoprotein cholesterol (VLDL-C).

10. Title of the tables should not be end with a full stop.

11. Even though the findings are more interesting, interpretation and discussion part is poor. The author reported the association of the atherogenic index with menopausal status with respect to adjusted for age and BMI. The discussion part is poor to justify this analysis.

12. There are some typo errors especially in abbreviations (mainly on abstract) and grammatical errors in the manuscript.

Is the work clearly and accurately presented and does it cite the current literature? Partly

Is the study design appropriate and is the work technically sound? Partly

Are sufficient details of methods and analysis provided to allow replication by others? Partly

If applicable, is the statistical analysis and its interpretation appropriate? Yes

Are all the source data underlying the results available to ensure full reproducibility? Yes

Are the conclusions drawn adequately supported by the results? Partly

Competing Interests: No competing interests were disclosed.

Reviewer Expertise: Metabolic diseases, Enzymology (Cytochrome P450)

I confirm that I have read this submission and believe that I have an appropriate level of expertise to confirm that it is of an acceptable scientific standard, however I have significant reservations, as outlined above. 
The benefits of publishing with F1000Research:

- Your article is published within days, with no editorial bias

- You can publish traditional articles, null/negative results, case reports, data notes and more

- The peer review process is transparent and collaborative

- Your article is indexed in PubMed after passing peer review

- Dedicated customer support at every stage

For pre-submission enquiries, contact research@f1000.com 